There was no significant difference in $\operatorname{GORD}(\mathrm{p}=0.305)$, rhinosinus disease $(\mathrm{p}=0.388)$ or oral corticosteroid requirement $(\mathrm{p}=0.6896)$. Asthma Control Questionnaire (ACQ) was significantly higher in OSA $3.3 \pm 1.3$ compared to the no-OSA group $2.8 \pm 1.3, p=0.022$ (Apnoea Hypoxia Index (AHI) $\geq 10$ )

Conclusion Asthmatics with co-morbid OSA are more likely to have poor asthma control with significantly higher ACQ scores. Additionally, these patients have significantly higher rates of diabetes, dyslipidaemia and hypertension. Routine screening for OSA and metabolic syndrome ("syndrome z") is recommended in asthmatics.

\section{P196 A NEW QUESTIONNAIRE TO MEASURE QUALITY OF LIFE IN SEVERE ASTHMA (SAQ): PRELIMINARY VALIDATION}

${ }^{1} \mathrm{R}$ Jones, ${ }^{2} \mathrm{M}$ Masoli, ${ }^{3} \mathrm{M}$ Hyland, 'J Lanario. ${ }^{1}$ Peninsula School of Medicine and Dentistry, University of Plymouth, Plymouth, UK; ${ }^{2}$ Plymouth Hospital's NHS Trust, Plymouth, UK; ${ }^{3}$ School of Psychology, University of Plymouth, Plymouth, UK

\subsection{6/thoraxjnl-2017-210983.338}

Introduction and Objectives Existing HRQoL scales have poor content validity for severe asthma as they fail to measure the qualitatively different burdens experienced by the severe asthma population compared to those with mild or moderate asthma, in particular, the side effects of oral corticosteroids (OCS). A new severe asthma quality of life questionnaire (SAQ) has been designed using extensive patient input in qualitative studies as per FDA guidelines. The questionnaire has 16 questions rated on a 1-7 Likert scale and a 100 point global quality of life scale (GQoL) similar to the EQ-5Ds 100 point visual analogue scale (VAS) (SAQ.org.uk).

Methods Consecutive consenting patients attending the severe asthma clinic in Plymouth with severe asthma were invited to participate in a cross sectional survey. Patients completed four questionnaires the SAQ, mini Asthma Quality of Life Questionnaire (miniAQLQ), Asthma Control Test (ACT) and the EQ-5D. Prednisolone dose and frequency of severe exacerbations were obtained from clinic records.

Results 102 participants (64 female, mean age $=51$ years range 18-79 years), of whom 38 were on maintenance OCS consented to take part, mean FEV1\% of 69\%. Correlations between the four questionnaires were all above 0.65. Correlations with frequency of severe exacerbations were SAQ 0.31, miniAQLQ 0.31, ACT 0.34. The SAQ's GQoL correlated with the EQ-5D's VAS at 0.73 . The SAQ was significantly better than the miniAQLQ at predicting the quality of life of patients taking $\geq 10 \mathrm{mg}$ OCS a day $(\mathrm{p}<0.05$ vs $\mathrm{p}=0.88)$. These questionnaires had parallel Results for doses up to $10 \mathrm{mg}$ but above that only SAQ provided differentiation between patients.

Conclusions Preliminary Results indicate that the SAQ may be a more valid measure of quality of life in severe asthma than existing questionnaires. The SAQ maps onto a pre-existing health economic measure, the EQ-5D. Furthermore the SAQ has greater sensitivity to differences in OCS dose compared to the AQLQ. The SAQ will be assessed further in a larger validation study.

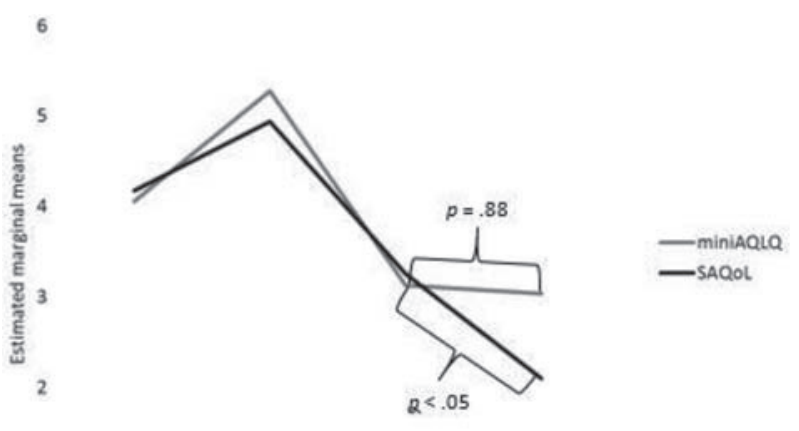

1

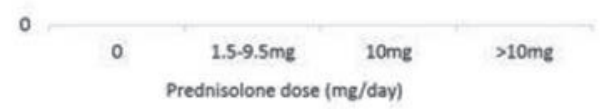

Abstract P196 Figure 1

\section{P197 THE IMPROVING ASTHMA CARE TOGETHER (IMPACT) PROJECT}

D Subramanian, S Greenwood, E Dryden, H Paine, S Ali, C Bennet, H Lagnado, L Sutton. Royal Derby Hospital, Derby, UK

\subsection{6/thoraxjnl-2017-210983.339}

The Improving Asthma Care Together (ImpACT) project implements a novel model of care which provides an integrated responsive services for asthma patients in Derby.

Aim The hypothesis of this project was that rapid review by a specialist asthma nurse in the community during an asthma exacerbation, would result in an improvement in patient's asthma control and their ability to self-manage their asthma.

Methods Four specialist asthma nurses were recruited to provide seven day cover for the service. Patients who reported increasing asthma symptoms could access the service by selfreferral or referral from a healthcare professional. The intervention involved a face-to-face review or a telephone call from a specialist asthma nurse. Patients were offered a $30 \mathrm{~min}$ face to face review at a variety of GP locations in the region. A template for each ImpACT review was constructed and a management plan issued at each consultation. A questionnaire was devised and patients were asked to complete this approximately 6 weeks following the intervention. A 10 point scale was used to ask patient's what their confidence levels were in self-managing their asthma $(0=$ no confidence and $10=$ highly confident) and how they rated their asthma control $(0=$ poor and $10=$ excellent).

Results This project commenced in January 2017. Between the start date and June 2017 a total of 884 patients were reviewed as part of the service. 397 face-to- face visits, 470 telephone consultations and 17 home visits. Patient's self-rating of their asthma control significantly improved following the intervention (pre-intervention mean 3.4, standard deviation [SD] 2.2 versus post-intervention mean 8.1 [SD 1.4]; paired ttest $<0.001 ; n=23)$. Patient's self-reported confidence in 
managing their own asthma also significantly improved following the intervention (pre-intervention mean 4.1 [SD 2.5] versus post-intervention mean 8.9 [SD 1.1]; paired t-test $<0.001$; $\mathrm{n}=24$ ). Total number of hospital admissions and emergency department attendances did not decrease compared to the previous year's data during this period (308 in 2016 versus 352 in 2017).

Conclusion Results to-date show that this integrated and responsive service for asthma exacerbation is well utilised and demonstrates a significant improvement in patient reported asthma control and confidence in self-managing their condition.

\section{P198 FENO AND BLOOD EOSINOPHILS AS BIOMARKERS IN PREDICTING ASTHMA EXACERBATIONS}

${ }^{1} S$ Rastogi, ${ }^{2} S$ Bosnic-Antievich, ${ }^{3}$ Pavord, ${ }^{4} \mathrm{~N}$ Roche, ${ }^{5} \mathrm{D}$ Halpin, ${ }^{6} \mathrm{~L}$ Bjermer, ${ }^{7} \mathrm{O}$ S Usmani, ${ }^{8} \mathrm{G}$ Brusselle, ${ }^{9} \mathrm{~S}$ Wan Yau Ming, ${ }^{10} \mathrm{~S}$ Halim, ${ }^{1} \mathrm{G}$ Gopalan, ${ }^{9,11} \mathrm{D}$ Price. ${ }^{1}$ AstraZeneca, Gaithersburg, US; ${ }^{2}$ Woolcock Institute of Medical Research, University of Sydney, Sydney, Australia; ${ }^{3}$ University of Oxford, Oxford, UK; ${ }^{4}$ University Paris Descartes, Paris, France; ${ }^{5}$ Royal Devon and Exeter Hospital, Exeter, UK; ${ }^{6}$ Lund University, Lund, Sweden; ${ }^{7}$ Imperial College London, London, UK; ${ }^{8}$ University of Ghent, Ghent, Belgium; ${ }^{9}$ Observational and Pragmatic Research Institute, Singapore; ${ }^{10}$ Astrazeneca, Luton, UK; ${ }^{11}$ University of Aberdeen, Aberdeen, UK

\subsection{6/thoraxjnl-2017-210983.340}

Introduction and Objectives Blood eosinophil counts (Bl-Eos) and fractional exhaled nitric oxide concentrations (FeNO) are established biomarkers in asthma. While patients with raised $\mathrm{Bl}$-Eos are at increased risk of asthma exacerbations, it is unclear whether raised $\mathrm{FeNO}$ is associated with further increased risk. We sought to determine if raised Bl-Eos combined with raised FeNO was associated with increased frequency of asthma exacerbations.

Methods This was a cross-sectional study of data from the Optimum Patient Care Research Database. Patients included were aged $18-80$ years with $\geq 1$ year of continuous electronic health records prior to their most recent FeNO readings, had evidence of asthma, had received $\geq 1$ inhaled corticosteroid prescription, and had Bl-Eos recorded within 5 years of FeNO reading. Cohorts were determined by: Bl-Eos raised $\left(\geq 0.25 \times 10^{9} / \mathrm{L}\right.$, a cutoff representing the sample mean) and not raised $\left(<0.25 \times 10^{9} / \mathrm{L}\right)$ and, FeNO raised $(\geq 35 \mathrm{ppb})$ and not raised $(<35 \mathrm{ppb})$. Patients were directly matched on age, sex, and smoking status. Patients with (i) raised Bl-Eos and not raised $\mathrm{FeNO}$, (ii) raised $\mathrm{FeNO}$ and not raised $\mathrm{Bl}$-Eos, or (iii) both biomarkers raised were compared with reference patients (neither biomarker raised). Comparison of exacerbations (evidenced by acute oral corticosteroid prescription or unplanned asthma-related hospital attendance) was conducted using conditional Poisson regression.

Results The unmatched study population consisted of 610 patients (mean age 52, 38\% male, 46\% non-smokers). With 1:1 matching, both the (i) raised $\mathrm{Bl}-\mathrm{Eos}$ and not raised FeNO cohort $(n=186)$ and the (ii) raised FeNO and not raised BlEos cohort $(n=98)$ demonstrated a trend toward greater exacerbation rates (unadjusted rate ratio: 1.41 [95\% CI 0.91, 2.19] and 1.35 [95\% CI 0.991 .84 ], respectively) vs. reference group. Importantly, however, when both biomarkers were raised $(n=53)$, a significantly greater exacerbation rate was observed (1.72 [95\% CI 1.00, 2.93]).
Conclusion The combination of raised FeNO and raised BlEos was associated with a greater exacerbation rate compared with neither biomarker raised. FeNO and Bl-Eos are simple primary care measurements that could reliably predict exacerbation risk for asthma patients. This should be confirmed prospectively in larger populations.

Please refer to page A258 for declarations of interest in relation to abstract P198.

\section{P199 ADVERSE EVENTS PROFILE OF ORAL CORTICOSTEROIDS AMONG ASTHMA PATIENTS IN THE UK}

${ }^{1} \mathrm{M}$ Bloechliger, ${ }^{1} \mathrm{D}$ Reinau, ${ }^{1} \mathrm{~J}$ Spoendlin, ${ }^{2} \mathrm{SC}$ Chang, ${ }^{3} \mathrm{~K}$ Kuhlbusch, ${ }^{4} \mathrm{LG}$ Heaney, ${ }^{5} \mathrm{SS}$ Jick, ${ }^{1}$ CR Meier. ${ }^{1}$ Basel Pharmacoepidemiology Unit, Basel, Switzerland; ${ }^{2}$ Genentech, Inc. , South San Francisco, CA, US; ${ }^{3}$ F. Hoffmann-La Roche, Basel, Switzerland; ${ }^{4}$ Wellcome-Wolfson Institute for Experimental Medicine, Queens University Belfast, Belfast, UK; ${ }^{5}$ Boston Collaborative Drug Surveillance Program, Boston University School of Public Health, Lexington, MA, US

\subsection{6/thoraxjnl-2017-210983.341}

Background and Objectives Previous studies have linked oral corticosteroid use in asthma patients to various adverse events. This study aimed to assess in more depth than has previously been done the toxicity profile of oral prednisolone among adult asthma patients.

Methods Using data from the UK-based Clinical Practice Research Datalink, we conducted a series of cohort studies, each with a nested case-control analysis, to quantify the risk of 11 different potential corticosteroid-related adverse events.

Results Incidence rates per 1000 person-years of potential corticosteroid-related adverse events in patients with new current use of oral prednisolone ranged from 1.4 (95\% confidence interval [CI], 1.0-1.8) for peptic ulcer to 78.0 (95\% CI, 74.8-81.2) for severe infections. After adjusting for confounding, current oral prednisolone use was most strongly associated with an increased risk of severe infection (odds ratio [OR] 2.16; 95\% CI, 2.05-2.27) compared with non-use of prednisolone. There were smaller elevated risks of peptic ulcer (OR 1.47; 95\% CI, 1.12-1.92), affective disorders (OR 1.47; 95\% CI, 1.32-1.63), herpes zoster (OR 1.32; 95\% CI 1.191.48), cardiovascular events (OR 1.33; 95\% CI 1.18-1.49), diabetes mellitus type 2 (OR 1.35; 95\% CI 1.22-1.49), bone related conditions (OR 1.27; 95\% CI 1.17-1.37), and cataract at higher cumulative doses (cumulative dose $\geq 2000 \mathrm{mg}$ : OR 1.43 ; 95\% CI 1.17-1.73), compared with non-use of prednisolone. We did not observe an association between current oral prednisolone use and glaucoma, chronic kidney disease, or hypertension. Past use of oral prednisolone was not associated with any of the study outcomes. We observed possible doseresponse relationships between current oral prednisolone use and the risk of cardiovascular events, affective disorders, bone-related conditions, severe infections, diabetes mellitus type 2, and cataract, but not the other investigated outcomes. Conclusion Oral prednisolone use is associated with an increased risk of infections, gastrointestinal, neuropsychiatric, ocular, cardiovascular, metabolic, and bone-related complications among adult asthma patients. The risk is associated with current but not past use of oral prednisolone use, and for some outcomes with the prescribed dose of oral prednisolone. 


\section{P200}

THE CLINICAL, UTILITY AND ECONOMIC BENEFITS OF SECURING MINIMAL IMPORTANT DIFFERENCE IN ASTHMA CONTROL TEST USING A NOVEL TOOL: THE A. B.O.V.E. ASTHMA (ACHIEVING-BETTER-OUTCOMES-ANDVALUE-FOR- EVERYBODY-IN-ASTHMA)

${ }^{1} \mathrm{~A}$ Manfrin, ${ }^{2} \mathrm{M}$ Tinelli. 'Medway School of Pharmacy, Universities of Greenwich and Kent at Medway, Anson Building, Chatham, UK; ${ }^{2}$ LSE Health and Social Care, The London School of Economics and Political Science, London, UK

\subsection{6/thoraxjnl-2017-210983.342}

Introduction and Objectives Asthma accounts for an economic loss of $€ 72$ billion annually in the 28 countries of the European Union with a monetised value of DALYs cost of $€ 38$ billion. One of the key priorities in asthma management is achieving asthma control. It is crucial to understand whether providing a minimally clinical important difference (MID) of the asthma control test (ACT) score can bring better clinical, utility and economic outcomes.

Aim To test whether the A.B.O.V.E. ASTHMA (Achieving-Better-Outcomes-and-Value-for-Everybody-in-Asthma) tool works in terms of securing the MID in ACT and, in doing so, we can provide positive outcomes for patients, payers, providers and policy makers.

Methods Using the data obtained from the Italian Medicines Use Review (I-MUR) cluster randomised controlled trial (CRCT; 2014-2015) involving 1263 asthma patients and 283 pharmacists in Italy, we tested whether A.B.O.V.E. ASTHMA was able to (1) link a clinical outcome (ACT score) to economic and utility dimensions; (2) secure a MID improvement in ACT and the outcomes attached in terms of cost savings

Abstract P200 Table 1 Annual cost savings and utility gains when securing clinical target in asthma control (MID) with A.B.O.V.E. ASTHMA intervention

\begin{tabular}{|c|c|c|c|c|c|c|c|c|c|}
\hline \multicolumn{4}{|c|}{$\begin{array}{l}\text { Possible shifts* } \\
\text { (current to target scenario) }\end{array}$} & \multicolumn{3}{|c|}{$\begin{array}{l}\text { @ } 3 \text { months Total } \\
n=1000\end{array}$} & \multicolumn{3}{|c|}{$\begin{array}{l}\text { @ } 6 \text { months Total } \\
n=1000\end{array}$} \\
\hline & & $\begin{array}{l}\text { Current scenario } \\
\text { (ACT) }\end{array}$ & $\begin{array}{l}\text { Target } \\
\text { scenario } \\
\text { (ACT) }\end{array}$ & $\begin{array}{l}\% \text { of } \\
\text { success }\end{array}$ & $\begin{array}{l}\text { Cost savings NHS } \\
\text { (euros) }\end{array}$ & $\begin{array}{l}\text { Utility gains } \\
\text { (years in full health } \\
\text { saved) }\end{array}$ & $\begin{array}{l}\% \text { of } \\
\text { success }\end{array}$ & $\begin{array}{l}\text { Cost savings NHS } \\
\text { (euros) }\end{array}$ & $\begin{array}{l}\text { Utility gains } \\
\text { (years in full health } \\
\text { saved) }\end{array}$ \\
\hline \multirow[t]{2}{*}{1} & RED to RED & $5-10$ & $8-13$ & 2.6 & 0 & 0 & 1.6 & 0 & 0 \\
\hline & $\rightarrow$ & & & & & & & & \\
\hline \multirow[t]{3}{*}{2} & RED to YELLOW & $15-16$ & $14-17$ & 5.4 & 100132 & 4.9 & 5.5 & 102408 & 4.96 \\
\hline & & & & & (CI 75,099; 130,172) & (Cl $4.85 ; 4.94)$ & & (CI 76,806; & (Cl $4.91 ; 5.00)$ \\
\hline & $\rightarrow$ & & & & & & & $133,130)$ & \\
\hline \multirow[t]{2}{*}{3} & $\begin{array}{l}\text { YELLOW to } \\
\text { YELLOW }\end{array}$ & $15-16$ & $18-19$ & 2.2 & 0 & 0 & 0.9 & 0 & 0 \\
\hline & $\rightarrow$ & & & & & & & & \\
\hline \multirow[t]{4}{*}{4} & YELLOW to & $18-19$ & $20-21$ & 10.5 & 245880 & 30.56 & 13.8 & 323075 & 40.16 \\
\hline & GREEN & & & & (CI 184,410; 319,644) & (CI 30.29; 30.83) & & (CI 242,306; & (CI 39.80; 40.52) \\
\hline & & & & & & & & $419,998)$ & \\
\hline & $\rightarrow$ & & & & & & & & \\
\hline \multirow[t]{5}{*}{5} & $\begin{array}{l}\text { GREEN to } \\
\text { GREEN }\end{array}$ & $20-21$ & $\geq 23$ & 5.3 & 0 & 0 & 6.0 & 0 & 0 \\
\hline & $\rightarrow$ & & & & & & & & \\
\hline & Total & & & 31.07 & 346012 & 35.42 & 27.82 & 425483 & 45.12 \\
\hline & $(1+2+3+4+5)$ & & & & (CI 259,509; & (CI 35.11; 35.73) & & (CI 319,112; & (Cl 44.72; 45.52) \\
\hline & & & & & $449,816)$ & & & $553,128)$ & \\
\hline
\end{tabular}

